\title{
Education, Training, and Regional Development: A Policy Relevant Agenda for Regional Science
}

Harrison S. Campbell, Jr.*

\section{INTRODUCTION}

When asked to prepare a few comments on the future of regional science, I was also requested to relate these comments to the general direction of my own research. In preparing these remarks, I am reminded of two recent issues of the International Regional Science Review that were devoted to the outlook for regional science as it reached the age of 40 . At that time, I noted that the fact the discussion was taking place at all was a good indicator of the discipline's future health (Campbell 1995). Several themes emerged from those volumes, including (1) a general need for regional scientists to relate the relevance of their research to "real world" issues; (2) the general perception that we have not fully realized our interdisciplinary heritage; (3) that the pursuit of interdisciplinary work will broaden our theoretical scope and expand our conceptual horizons, thereby making our work more relevant to scholars in other disciplines; and (4) a need to explicitly tie our work to public policy issues and initiatives. The fact that much of our research is premised on its application to public policy means that we are not far from realizing these goals. We must, however, seek to reach a broader audience if participation in regional science organizations is to be truly interdisciplinary.

There are, in my opinion, several factors that move us in these directions. One factor concerns public sector decision makers at all levels of government who seek our analytical expertise and advice on an array of public policy questions. This kind of interaction indicates that we have something to contribute to public discourse. Indeed, many graduates of regional science programs find employment in government and public policy/public affairs research and teaching units (Gershberg 1995). A second factor comes from administrators in our home institutions. Chancellors, provosts, and deans are frequently asked by state legislators and the general public to comment on how universities are contributing to the general welfare of their host regions. Consequently, administrators are beginning to advocate the practicing of our trade in the public arena, thereby demonstrating the role universities can play in their communities, regions, and states. This frequently takes the form of community service, outreach, and continuing education. Finally, our students want to be exposed to the practical application of what we teach and how these applications are relevant to their future. 
Given recent discussions about the future of regional science, I believe that we are headed in the right direction on the issues of relevance and public policy application. At the same time, it does not appear that we are making much progress in expanding our interdisciplinary horizons. What follows is not a call for new directions in regional science, but a few ideas about how to extend our work, making it more generally relevant, more public policy oriented, and more attractive to scholars in other disciplines-particularly those concerned with the state of education, labor markets, and regional development. I confine my remarks to what I see as (1) a shift in the focus of regional development theory; (2) potentially useful experiments in projecting occupational and educational structures associated with development; and (3) how resources devoted to education and training might be effectively targeted.

\section{EDUCATION AND SHIFTING DEVELOPMENT THEORY}

Education is generally accepted to be important to the process of regional development. To date, however, there have been relatively few attempts to directly link (model) the output of education and training systems with the skills regional employers demand (Campbell 1994; Haynes 1997). While Moriarty's (1980) book essentially defined the scope of community and regional development in its day, the underlying premise of regional development appears to be shifting in emphasis. Whereas traditional regional development theory was primarily concerned with the attraction of outside capital and the location of industry, increasing emphasis is being placed on development as it specifically relates to the community.

Teitz (1994) notes that older theories of regional development were macroscopic in the sense they did not spatially disaggregate the region. The attraction of outside capital was the main objective in this paradigm with little attention paid to distributional issues associated with development. Teitz (1994) also notes that more recently, Blakely (1989) and Bigham and Mier (1993) have articulated a new regional development paradigm that more clearly emphasizes distributional issues in development among communities of urban regions. In essence, "the economic development process [is] an endogenous effort to enhance a local community's ability to create and retain employment" (Teitz 1994, p.102). This kind of "development from within" rests on the successful utilization of communitybased resources, the most important of which are its human resources. Clearly, policies relating to education and training would form an important part of this body of development theory. Not only has education been shown to affect one's access to labor market information, thereby affecting labor market experiences (Ihlandfeldt 1997), but Malecki (1994) suggests that the relationship between education and entrepreneurship may also be an important one. Increasingly, this line of inquiry is being cast in terms of social capital, institutional capacity, and institutional flexibility as we recognize the importance of social cohesion in facilitating the exchange of information across networks of individuals, firms, and institu- 
tions of all types. Particularly important are those networks that maximize the diversity of information exchange (Meyer 1998). As institutions, partnerships, and networks take on more prominence in the economic development process, we should begin to examine how these actors bring collective resources to bear on the design and implementation of various education and training schemes.

Where do regional scientists fit in this picture? First, we must assess the extent to which this more locally focused paradigm represents a real shift in our theories of development. If this change in focus-from functional economic region to community, from exogenous forces to endogenous growth-is qualitatively different, then we must also assess the productivity-enhancing qualities of local development strategies that include a training component and the requisite factors for institutional coordination. While any education or training strategy should consider the current and future industrial mix of a region, Fitzgerald (1993) has pointed out that narrowly focused programs that train individuals for specific occupations may be of limited value. Rather, the most successful training programs are those that train people in an entire line of work, including production skills, management, financial planning, and health and safety requirements. The point at which theory turns to practice provides an excellent opportunity for interdisciplinary collaboration. Quite apart from the theoretical basis of this brand of development are institutional issues surrounding what kinds of training should be provided, how education delivery mechanisms are designed and implemented, and how such programs are structured to meet the needs of both workers and employers. In addition to benefitting from the contributions of "traditional" regional scientists (economists, geographers, urban planners), these are areas in which we might benefit from scholars in other fields such as public administration, educational policy studies, sociology, social and environmental psychology, and the like.

\section{EDUCATION AND TRAINING FOR WHAT?}

Yet another report detailing worker shortages in information technology sectors is soon to be released (see Leffel 1998). Large and growing numbers of vacancies are reported to exist for computer programmers/engineers and systems analysts, 95 percent of which require at least two years of education beyond high school. Reports such as these are becoming increasingly common (Johnston and Packer 1987; U.S. Department of Labor 1989) as are criticisms of them (Mincey 1990; Mishel and Teixeira 1991). Braddock (1992) reports that the basic skill levels to perform "unskilled" jobs are likely to increase while Bailey (1991) notes that, independent of any educational upgrading, recent occupational projections suggest a steady increase in those occupations that currently employ more highly educated workers. Whatever the causes of employer demands for education and training, occupational forecasts have been used as a basis for educational policy making. 
Although it is widely held that changes in technology and the composition of product markets affect the nature of work and the demand for skills, our understanding of the type of education needed to respond to changing occupational demands is limited. The role of technological change in the composition of inputoutput tables has been widely studied and the application of this line of inquiry might hold promise for a deeper understanding of the ways in which changing industrial structure is translated into changing occupational and educational structures. One rather novel approach originated by Conway (1990) and elaborated in Israilevich et al. (1997) has been to simulate the process of coefficient change via a set of regression equations that relate measures of actual output to the output that would be expected given constant technology implied by an input-output table. A similar procedure could be used to simulate changes in occupational staffing patterns over time. However, since the availability of regional industry-occupation and occupation-education matrices is limited, we have little information on which to base future occupational demands or the educational requirements associated with them.

As an attempt to remedy this situation, I recommend two separate, but related, forms of analysis. The first concerns experiments in projecting the occupational structure of industries in a manner analogous to the projection of inputoutput coefficients. Though regional occupations matrices are difficult to obtain, Alam (1990) has shown using data from India that standard biproportional techniques can be extremely helpful in projecting these structures under conditions of limited information. Because the same, or similar, educational profile might correspond to several occupational groupings, de Grip, Groot, and Heijke (1991) have performed cluster analysis on occupation-education matrices for the Netherlands to identify clusters of occupations that involve similar education and training requirements. If combined, these efforts should help enlighten the process and policies of education and training while providing state and local decision makers with a consistent framework on which to base, and refine, the provision of specialized education and training. It is my hope that analyses such as these will shed new light on both the occupational and educational requirements of employment during a time of rapid product and process innovation, while at the same time providing a framework by which appropriate skills can be identified and imparted.

\section{EDUCATION, THE STATE, AND REGIONAL SCIENCE}

As regional scientists we might reasonably ask: Where (in what regions/sectors) would these resources be most effectively targeted? Every few years, the Bureau of the Census reports on earnings by educational attainment. In a recent study, it reported that college graduates average 73 percent more earnings over their lifetime than do those with only a high school education and that the differential jumps to 93 percent for members of the labor force with master's degrees. Such rates of return to human capital investment are clear signals that higher education is in great demand by employers. Except for the work of Ben- 
nett, Glennerster, and Nevison (1995) in Britain, there is scant evidence of how these rates of return vary across space and there have been no similar studies conducted in the United States.

Why should we be interested in spatial variations in the return to educational investment? First, people, particularly young people, tend to respond to local market conditions that are likely to affect rates of return to human capital investment. Second, high rates of return to education and training are typically interpreted as signals of underinvestment. If wages reflect worker productivity, then regions exhibiting unusually high rates of return to human capital investment might benefit from policy initiatives aimed at encouraging educational persistence. Third, the fact that benefits from educational spending can spill over from one region to another suggests that there may be a tendency for states and localities to underinvest in human capital (Rasmuessen 1994). To the extent that this reflects a kind of market failure on the part of government, regional analysis of age-earnings profiles, particularly if examined over time, could lend additional insight to resource allocation decisions and educational policy planning. This does not necessarily imply that governments become direct providers of education and training. Increasingly, the role of government is to act as a facilitator of public-private partnerships that can include workplace-based training, an approach that requires greater institutional flexibility.

If public policies that encourage training and educational persistence are pursued, they are probably best designed in such a way as to allow recipients to determine their own fields of study based on local market conditions. Using rate of return studies as indicators of local/ regional market conditions would allow educational policy planning to move away from rigid manpower planning exercises toward labor market-based initiatives.

\section{CLOSING REMARKS}

The relevance of regional science to public policy issues is one of the discipline's greatest strengths. Indeed, the fact that our theoretical foundations are drawn from several fields of study, coupled with an aim to inform the policymaking process, attracts many to regional science. Clearly, regional science has much to offer. While I have attempted to outline a few directions for regional science with reference to education and development, I also hope that my remarks will encourage a more interdisciplinary pursuit of our collective goals.

\section{REFERENCES}

Alam, M. "Explorations with RAS in Projecting an Occupation-Education Relationship in India." Socio-Economic Planning Sciences 24 (1990), 107-124. Bailey, T. "Jobs of the Future and the Education They Will Require: Evidence From Occupational Forecasts." Educational Researcher 20 (1991), 11-20.

Bennett, R., H. Glennerster, and D. Nevison. "Regional Rates of Return to Education and Training in Britain." Regional Studies 29 (1993), 279-295. 
Bingham, R., and R. Mier. Theories of Local Economic Development. Newbury Park, CA: SAGE, 1993.

Blakely, E. Local Economic Development and Planning. Newbury Park, CA: SAGE, 1989.

Braddock, D. "Scientific and Technical Employment, 1990-2005." Monthly Labor Review 115 (February 1992), 28-42.

Campbell, H.S. Jr. "Education and Labor Supply: An Extended Demographic Model of the Chicago Region." Ph.D. dissertation, University of Illinois, 1994.

"A Newcomer's Perspective on Regional Science." International Regional Science Review 18 (1995), 253-257.

Conway, R. "The Washington Projection and Simulation Model: A Regional Interindustry Econometric Model." International Regional Science Review 13 (1990), 141-166.

de Grip, A., L. Groot, and J. Heijke. "Defining Occupational Groupings by Education Structure." Environment and Planning A 23 (1991), 59-85.

Fitzgerald, J. "Labor Force, Education, and Work." In R. Bingham and R. Mier (eds.) Theories of Local Economic Development. Newbury Park, CA: SAGE, 1993.

Gershberg, A. "Regional Science and Policy School Space." International Regional Science Review 18 (1995), 243-248.

Haynes, K. "Labor Markets and Regional Transportation Improvements: The Case of High Speed Trains." The Annals of Regional Science 31 (1997), 57-76.

Ihlanfeldt, K. "Information on the Spatial Distribution of Job Opportunities with in Metropolitan Areas." Journal of Urban Economics" 41 (1997), 218-242.

Israilevich, P., G. Hewings, M. Sonis, and G. Schindler. "Forecasting Structural Change with a Regional Econometric Input-Output Model." Journal of Regional Science 37 (1997), 565-590.

Johnston, W., and A. Packer. Workforce 2000: Work and Workers for the Twenty-First Century. Indianapolis, IN: Hudson Institute, 1987.

Leffel, L. (1998) http://www.vt.edu:10021/ur/news/ITAArelease.html

Malecki, E. "Entrepreneurship in Regional and Local Development." International Regional Science Review 16 (1994), 119-154.

Meyer, D. "Formation of Advanced Technology Districts: New England Textile Machinery and Firearms, 1790-1820." Economic Geography (Extra Issue) (1998), 31-45.

Mincey, R. "Workforce 2000: Silver Bullet or Dud?" Research Paper, The Urban Institute. Washington, D.C., 1990.

Mishel, L., and R. Teixeira. The Myth of the Coming Labor Shortage. Washington, D.C.: Economic Policy Institute, 1991.

Moriarty, B. Industrial Location and Community Development. Chapel Hill: University of North Carolina Press, 1980. 
Rasmussen, D. "Spatial Economic Development, Education, and the New." International Regional Science Review 16 (1994), 107-118.

Teitz, M. "Changes in Economic Development Theory and Practice." International Regioral Science Review 16 (1994), 101-108.

U.S. Department of Labor. Labor Market Shortages. Report of the Secretary of Labor. Washington, D.C., 1989. 
